\title{
INTRODUCTION
}

\section{Controversies in Breast Cancer 2010}

William R Miller*

This volume represents the proceedings of the 'Controversies in Breast Cancer 2010' meeting held in Edinburgh on 12 to 13th July 2010. The event was the fifth in an annual series that brings together international experts as a faculty to discuss, with an invited audience of scientists and clinicians, topics regarded as controversial because of a paucity of information, divergent results or counterintuitive data.

The topics selected for scrutiny in 2010 were: prognostic and predictive factors; the predicted epidemic of breast cancer; undue and disproportion influences; 'who would have thought it?'; and drug development programmes. The Chairs for each session have provided a general background and synopsis as an introduction to the topics under consideration.

In addressing these subjects, faculty members were asked simply to highlight issues and points of information rather than provide methodological detail or be totally comprehensive. Furthermore, in order to incite debate and stimulate thought, presenters were asked to be provocative, fly kites, and act as devil's advocate and present data from an unconventional perspective. Readers should bear this in mind when reviewing the following texts, which are intended to offer some singular standpoints and an encouragement to think beyond accepted dogma. Hopefully the outcome is a better understanding of breast cancer.

Thanks and appreciation are directed towards all the participants in Controversies 2010.

\section{Competing interests}

The author declares that he has no competing interests.

\section{Acknowledgements}

This article has been published as part of Breast Cancer Research Volume 12 Supplement 4, 2010: Controversies in Breast Cancer 2010. The full contents of the supplement are available online at http://breast-cancer-research.com/ supplements/12/S4

Published: 20 December 2010

doi:10.1186/bcr2730

Cite this article as: Miller WR: Controversies in Breast Cancer 2010. Breast

Cancer Research 2010, 12(Suppl 4):S1.
*Correspondence: w.r.miller@ed.ac.uk

2 Stoneycroft Road, South Queensferry, West Lothian, EH30 9HX, UK 